УДК 636:620. 193

\title{
ИССЛЕДОВАНИЯ ХИМИЧЕСКОГО СОСТАВА СПИРТОВОГО ЭКСТРАКТА ШРОТА РАПСА
}

\author{
() Е.Э. Чигиринец", В.И. Воробьева, А.С. Бережницкая \\ Национальный технический университет Украины \\ «Киевский политехнический институт», пр. Победы, 37, корп. 4, Киев, 03056 \\ (Украина), e-mail: corrosionlife@yandex.ru
}

Установлено, что перспективным сырьем для создания летучих ингибиторов атмосферной коррозии (ЛИАК) является использование отходов, образующихся при получении масла из семян рапса (семейства Brassicaceae), а именно шрота рапса. Целесообразным явилось исследования качественного и количественного определения его основных соединений. Показано, что ингибирующая эффективность имеет экстремальный характер с максимумом защитной способности на 2 сут. Изучено изменение состава экстракта в процессе испарения, а также определены соединения, остающиеся в нелетучем осадке. Предметом исследования является изопропанольный экстракт шрота рапса. Цель работы - исследование его компонентного состава, а именно летучих и нелетучих соединений.

На основании данных газовой хромато-масс-спектрометрии определен и изучен качественный состав паровой фазы изопропанольного экстракта шрота рапса. Установлено, что основными компонентами являются гликозиды: сахароза, гуанозин, ксантонозин; сиреневый альдегид, кетон - 3,5-диметоксиацетофенон, стероиды ( $\beta$ и $\gamma$-ситостерол, кампостерол и др.), а также насыщенные и ненасыщенные жирные кислоты, представленные пальмитиновой, олеиновой, линолевой и уксусной кислотами.

Ключевые слова: сталь, коррозия, летучий ингибитор, шрота рапса, изопропанольный экстракт, гликозиды, кетон, терпены, альдегид, хромато-масс-спектрометрия.

\section{Введение}

На сегодняшний день наиболее технологичным и экономически выгодным средством временной противокоррозионной защиты во время хранения и транспортировки является использование летучих ингибиторов атмосферной коррозии (ЛИАК). Несмотря на большой ассортимент ЛИАК, проблема поиска доступного исходного сырья для получения новых составов ингибиторов по-прежнему является перспективной. В связи с этим актуальным является вопрос создания новых ингибиторов коррозии, отличающихся не только эффективностью ингибирования, но и экологической безопасностью.

В последнее время наблюдается все большая тенденция по использованию средств противокоррозионной защиты на основе возобновляемого растительного сырья [1-3]. Перспективным сырьём для получения ингибирующих материалов являются многотоннажные отходы сельского хозяйства, в первую очередь те, которые концентрируются на крупных перерабатывающих предприятиях. Накапливающиеся отходы, с одной стороны, создают экологические проблемы, а с другой - являются полноценными источниками многих ингибирующих соединений, что может служить сырьевой базой для получения противокоррозионных композиций.

Так, авторами было установлено $[4,5]$, что перспективным сырьем для создания ЛИК является ис-

\footnotetext{
Чигиринеи Елена Эдуардовна - заведующая кафедрой физической химии, доктор технических наук, профессор, тел. (+38) 406- 83-89, e-mail: corrosionlife@yandex.ru Воробьева Виктория Ивановна - аспирант кафедры физической химии, тел. (+38) 093-822-30-41, e-mail: viktorkathebest@yandex.ru

Бережницкая Александра Степановна - доцент кафедры физической химии, кандидат химических наук
} пользование отходов, образующихся при получении масла из семян рапса (семейства Brassicaceae), а именно шрота рапса. При этом спиртовой экстракт шрота рапса обеспечивает достаточно высокую ингибирующую способность при защите металла от атмосферной коррозии ( 90\% в условиях периодической конденсации влаги в течение 20 сут.).

\footnotetext{
* Автор, с которым следует вести переписку.
} 
Усредненный состав масла, полученного после переработки рапса, хорошо изучен $[6,7]$. В то же время в научно-технической литературе отсутствуют данные по химическому составу экстрактивной части шрота рапса.

В связи с этим целью работы явилось исследование компонентного состава спиртового экстракта шрота рапса и его летучих фракций.

\section{Экспериментальная часть}

Экстракцию шрота рапса, образуемого при холодном отжиме семян рапса, производили изопропиловым спиртом путем настаивания мелко измельченного растительного сырья до частиц размером 1-2,5 мм (при соотношении $1: 10$ ) в течение 1 сут с последующей фильтрацией.

Компонентный состав летучих веществ экстракта шрота рапса исследовали методом хромато-массспектрометрии на газовом хроматографе «FINNIGAN FOCUS» в качестве детектора с газовым хроматографом. Условия хроматографирования были следующими: капиллярная колонка HP-5MS, l=30 м, $\mathrm{d}=0,25$ мм; температура инжектора $-+250{ }^{\circ} \mathrm{C}$; температура детектора $-+280{ }^{\circ} \mathrm{C}$; толщина фазы $-0,25$ мкм; газ носитель - гелий; поток газоносителя - 1,5 мл/мин; программа: $100{ }^{\circ} \mathrm{C} \rightarrow 10{ }^{\circ} \mathrm{C} /$ мин $\rightarrow 280{ }^{\circ} \mathrm{C}$; диапазон масc: 30-500 дальтон; Split; Split Flow - 15 мл/мин; объем пробы - 2 мкл. Идентификация компонентов осуществлена сопоставлением времен удерживания пиков на хроматограмме и полных масс-спектров отдельных компонентов с соответствующими данными чистых соединений библиотеки масс-спектров «NIST-5». Относительное количественное содержание химических компонентов экстракта рассчитано методом внутренней нормализации площадей пиков без корректирующих коэффициентов чувствительности.

Идентификацию органических соединений экстракта шрота рапса производили методом ИКспектроскопии.

Для исследований взяты свежеприготовленные изопропанольные экстракты, а также экстракты после выдержки в течение 2 и 4 сут на открытом воздухе при температуре $25^{\circ} \mathrm{C}$. Для естественного испарения объем экстракта составлял 10 мл, площадь зеркала поверхности испарения -1 см.

\section{Обсуждение результатов}

Согласно полученным данным хромато-мас-спектрального анализа в составе летучих фракций изопропанольного экстракта шрота рапса содержится 20 индивидуальных компонентов, присутствующих в количестве более 0,2 \% (рис. 1, табл. 1), среди которых доминируют гликозиды (27\% от всех идентифицированных летучих соединений): сахароза, гуанозин, ксантонозин; сиреневый альдегид (12\%), кетон 3,5-диметоксиацетофенон (11\%), стероиды ( $\beta$ и $\gamma$-ситостерол, кампестерол и др.), а также насыщенные и ненасыщенные жирные кислоты (34\%), представленные пальмитиновой, олеиновой, линолевой и уксусной кислотами. В минорном количестве содержится алкалоидов 3\% ((пирролидин, 1-(1-оксо-7,10гексадекадиенил и 2-пирролидин, 1-(9-октадеценил)) и около 4\% некоторых терпенов (7-дигидро диосгенин и эргоста-5,22-диен-3-ол).

Большинство перечисленных соединений известны как ингибиторы коррозии в различных средах или являются основными компонентами их составов. Так, органические соединения, содержащие атомы азота (табл. 1), являются весьма реакционно способными веществами, активно взаимодействующими с поверхностью переходных металлов [8]. Ингибирующей способностью обладают установленные в паровой фазе насыщенные и ненасыщенные жирные кислоты [9]. Идентифицированные фитостерины ( $\beta$-ситостерол, $\gamma$-ситостерол, кампостерол) и гликозиды (сахароза, гуанозин) в соответствии с литературными данными [10] также проявляют ингибирующие по отношению к металлической поверхности свойства. Следовательно, можно предположить, что именно эти компоненты и обеспечивают противокоррозионную эффективность изопропанольного экстракта в качестве летучего ингибирующего состава.

Поскольку установлено, что паровая фаза экстракта шрота рапса имеет многокомпонентный состав, то очевидно, что испарение из него летучих соединений будет происходить в определенной последовательности. Это, в свою очередь, будет отражаться на защитных свойствах адсорбционной пленки на поверхности металла в зависимости от времени его выдержки в парах экстракта.

Исследованиями авторов установлено, что максимальная защитная способность адсорбционной пленки на поверхности металла, сформированной из паровой фазы изопропанольного экстракта шрота рапса, отмечена на 2-е сутки выдержки, после чего происходит некоторое снижение ее защитной способности [4]. 


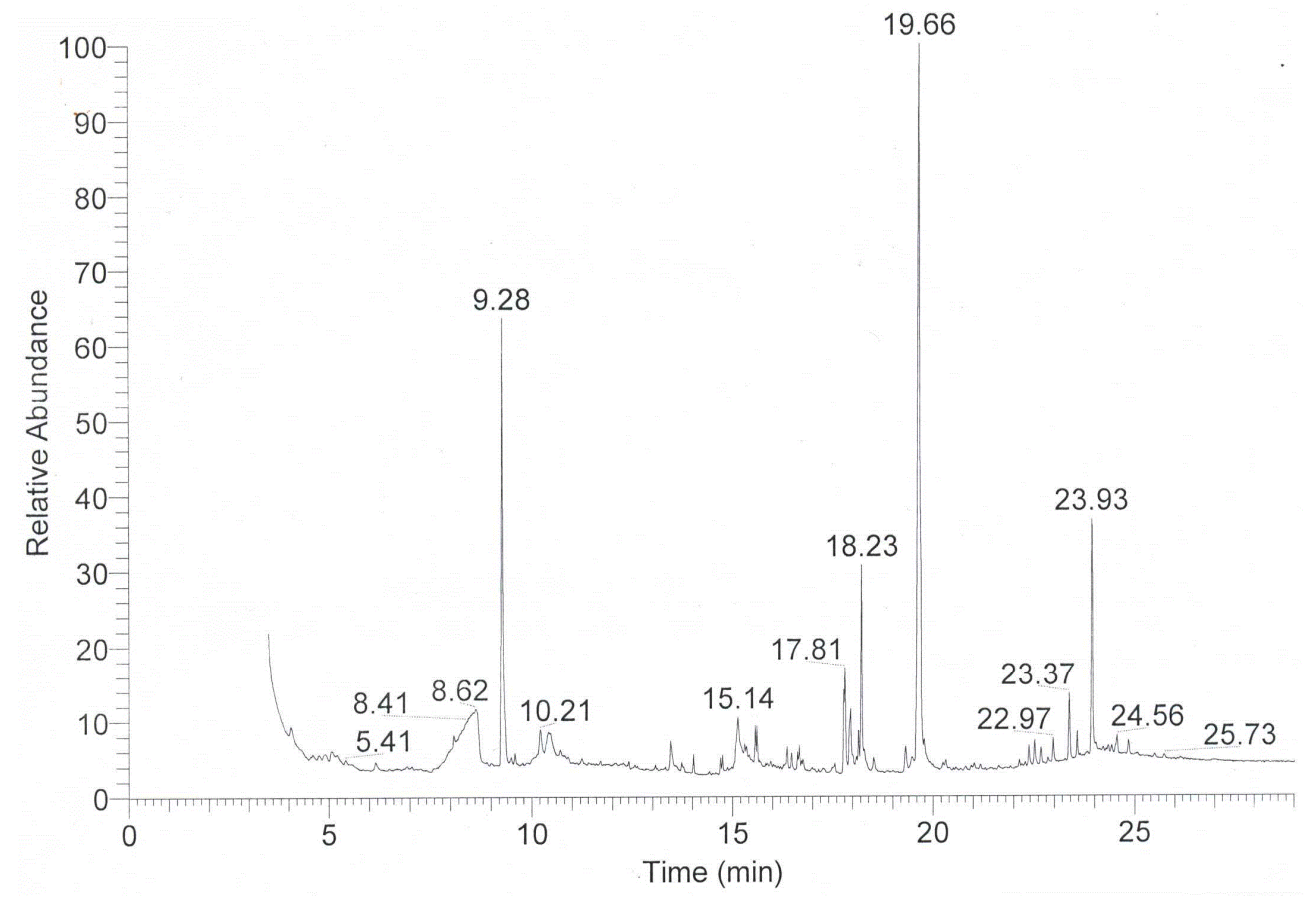

Рис. 1. Хроматограмма изопропанольного экстракта шрота рапса Brassicaceae

Таблица 1. Компонентный состав летучих веществ изопропанольного экстракта шрота рапса

\begin{tabular}{l|c|c}
\hline \multicolumn{1}{c|}{ Название компонента } & Время удерживания, t мин & Количественное соотношение, \% \\
\hline Гуанозин & 8,41 & 6,2 \\
Сахароза & 8,57 & 8,3 \\
Ксантонозин & 8,62 & 12,3 \\
3,5 -диметоксиацетофенон & 9,28 & 11,5 \\
Сиреневый альдегид & 10,21 & 5,6 \\
Уксусная кислота & 10,56 & 10,2 \\
Олеиновая кислота (октадекадиеновая) & 15,14 & 1,1 \\
Пирролидин, 1-(1-оксо-7,10- гексадекадиенил) & 16,63 & 1,1 \\
2-пирролидин, 1-(9-октадеценил) & 16,67 & 4,5 \\
Этанамин, 2,2'-окси-бис [N, N-диметил] & 17,81 & 6,1 \\
Пальмитиновая кислота & 18,23 & 9,8 \\
Линолевая кислота & 19,66 & 1,4 \\
7-дегидродиосгенин & 22,97 & 1,9 \\
Кампостерол & 23,01 & 1,1 \\
ү-ситостерол & 23,37 & 2,9 \\
$\beta$-ситостерол & 23,93 & 1,0 \\
Эргоста-5,22-диен-3-ол & 24,56 & 0,9 \\
Ситостенон & 25,73 & \\
\hline
\end{tabular}

Поэтому для более полного понимания механизма процесса испарения спиртового экстракта шрота рапса целесообразным было исследование изменения состава экстракта в процессе испарения, а также установление соединений, не принимающих участия в формировании пленки, т.е. остающихся в нелетучем осадке.

Так, методом ИК-спектроскопии были исследованы свежеприготовленный изопропанольный экстракт, состав после 2 сут. испарения, а также нелетучий остаток, образуемый в естественных условиях после 4 сут. испарения (рис. 2, табл. 2).

Для свежеприготовленного экстракта шрота рапса характерны полосы поглощения в области 2800$3000 \mathrm{~cm}^{-1}$, что, по-видимому, свидетельствует о присутствии межмолекулярной водородной связи.

Также на спектре присутствуют характерные полосы поглощения в области 690-900 см-1, которые относятся к колебаниям ароматического замещения (деформационные колебания связи С-H, а также деформационные колебания 1200-1300 см-1, соответствующие спиртовым группам). Это, вероятно, свидетельствует о присутствии в экстракте рапса ксантонозина и гуанозина. Полосы поглощения в области 800$1000 \mathrm{~cm}^{-1}$ соответствуют деформационным колебаниям связи $\delta\left(=\mathrm{CH}_{2}\right)$. 


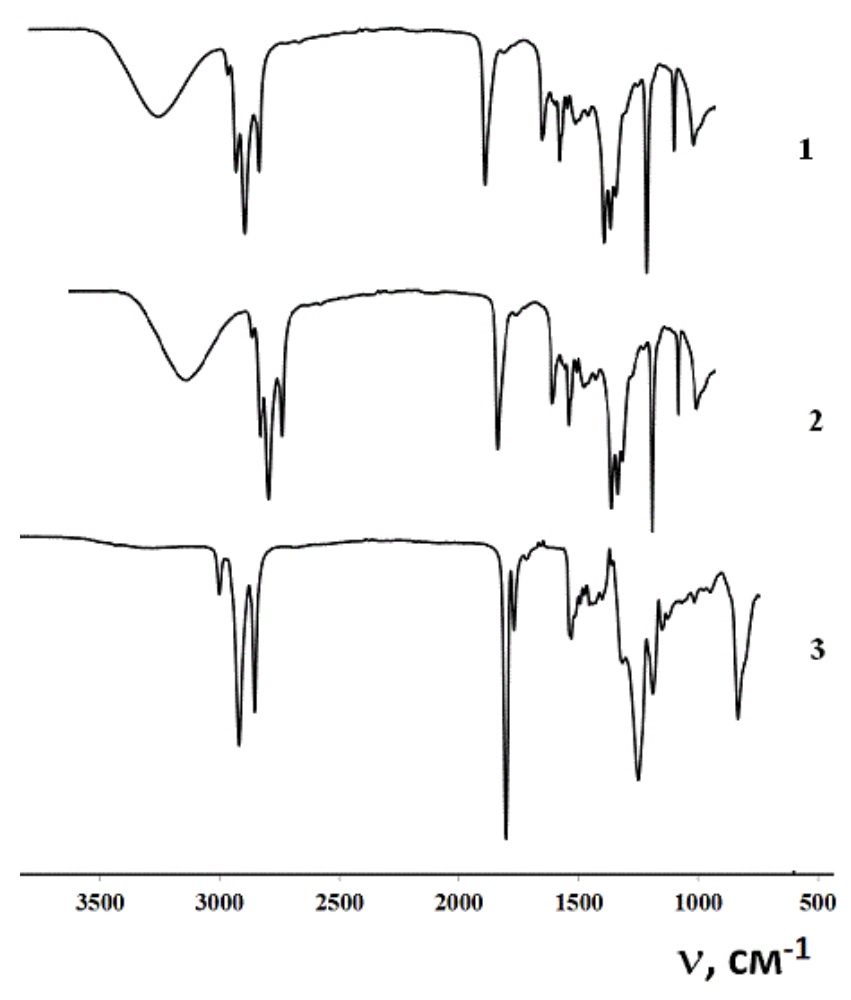

Рис. 2. ИК-спектры изопропанольного экстракта шрота рапса: 1 - свежеприготовленный экстракт шрота рапса; 2 - после испарения в течение 2 сут; 3 - после испарения в течение 4 сут

Также полосы поглощения в области 1600-1750 см-1 относятся к валентным колебаниям карбонильной группы кетонов, колебаний ароматического кольца, а также свободных и связанных карбоксильных групп, что свидетельствует о присутствии этих соединений в исследуемом экстракте и совпадает с данными газовой хромато-мас-спектрометрии. Полосу при $1160 \mathrm{~cm}^{-1}$ можно отнести к деформационным колебаниям спиртовых гидроксилов, что подтверждает присутствие в экстракте стероидов, относящихся к тетрациклическим спиртам.

Поглощение $v\left(\mathrm{COO}^{-}\right)$карбоновых кислот лежит в той же спектральной области, что и у альдегидов. Однако кислоты в исследуемом экстракте можно идентифицировать по большей интенсивности полосы $v \mathrm{C}=\mathrm{O}(\mathrm{v} 1500)$. Кроме того, в карбоновых кислотах проявляется интенсивное поглощение $v(\mathrm{O}-\mathrm{H})$ и v $(\mathrm{C}-\mathrm{O})$ в области 1420-1200 $\mathrm{cm}^{-1}$. Как известно, ввиду высокой поверхностной активности карбоновых кислот, что обусловлено дифильностью их строения, они способны адсорбироваться на поверхности. Кроме того, наличие двойной связи делает молекулу еще более реакционноспособной. Вероятней всего, механизм адсорбции будет значительно сложнее, чем в случае физической адсорбции, что обусловлено высокой реакционной способностью исходных соединений. Ввиду высокой донорной и акцепторной способности большинства веществ они могут реагировать между собой и с молекулами растворителя (экстрагента). На ИКспектрах после 4 сут. наблюдается значительное усиление интенсивности колебаний в области 1700$1750 \mathrm{~cm}^{-1}$, что нельзя однозначно отнести к оставшимся в сухом остатке альдегидам и кислотам, а скорее к частичным продуктам их взаимодействия и ароматических стероидов, которые, как известно, низколетучие.

Поскольку кислород карбоксильных групп имеет достаточно высокое сродство к металлической поверхности (большинству переходных металлов), в частности, выступает донорным атомом при комплексообразовании, то, безусловно, соединения, содержащие -СОО- группы, способны адсорбироваться на поверхности металла посредством не только ван-дер-ваальсовых взаимодействий, но и донорно-акцепторных связей.

Как видно из спектров, испарение в течение 2 сут. изопропанольного экстракта не приводит к существенному различию компонентного состава по сравнению со свежеприготовленным.

В то же время при испарении экстракта шрота рапса в естественных условиях в течение 4 сут. большая часть экстракта испаряется, что находит свое отображение в ИК-спектрах. Оставшийся нелетучий осадок представляет собой маслянистую вязкую жидкость и составляет 2-3\% от первоначальной массы экстракта. Исследование состава нелетучего остатка экстракта показало, что в нем присутствуют некоторые спирты и ароматические соединения, включая стероиды. 
Таблица 2. Отнесение полос поглощения $\left(\mathrm{cm}^{-1}\right)$ в ИК-спектрах экстрактов шрота рапса

\begin{tabular}{|c|c|c|c|c|}
\hline \multicolumn{2}{|c|}{$\begin{array}{l}\text { Полосы поглощения функциональных } \\
\text { групп } \\
\end{array}$} & $\begin{array}{c}\text { Свежеприготовленный } \\
\text { экстракт шрота рапса }\end{array}$ & $\begin{array}{l}\text { Состав после испаре- } \\
\text { ния в течение } 2 \text { сут }\end{array}$ & $\begin{array}{c}\text { Состав после испаре- } \\
\text { ния в течение } 4 \text { сут }\end{array}$ \\
\hline $\begin{array}{l}v_{\text {он- валентные }} \\
\delta \text { деформационные }\end{array}$ & $\begin{array}{l}3650-3590 \\
1450-1250\end{array}$ & $\begin{array}{c}1315 \\
1378,1275 \text { пл,1233 пл } \\
1229,1158\end{array}$ & $\begin{array}{c}1245,1307,1328,1390 \\
1296\end{array}$ & 1376,1436 \\
\hline $\begin{array}{l}v_{\text {Он- }} \text { связанные Н связью } \\
\text { (спирты, фенолы, } \\
\text { карбоновые кислоты) }\end{array}$ & $\begin{array}{l}3550-3200 \\
2700-2500 \\
\text { (широкая) }\end{array}$ & 3345 & 3337, 3000пл & 3005 \\
\hline $\begin{array}{l}v \mathrm{C}-\mathrm{H} \mathrm{sp}{ }^{3} \\
v_{\mathrm{OCH}_{3}}\end{array}$ & $\begin{array}{l}2975-2810 \\
\text { (сильные) }\end{array}$ & $\begin{array}{l}2922,2930,2986 п л, \\
2852\end{array}$ & 2953, 2936, 2867 & $\begin{array}{l}2919 \\
2850\end{array}$ \\
\hline$\delta \mathrm{C}-\mathrm{H} \mathrm{sp}{ }^{3}$ & $\begin{array}{l}1470-1430 \\
\text { (средние) } \\
1380-1370 \\
\text { (сильные) }\end{array}$ & $\begin{array}{l}1460 \\
1376\end{array}$ & 1471 & $\begin{array}{l}1454 \\
1379\end{array}$ \\
\hline $\begin{array}{l}v_{\text {сно }} \text { альдегиды } \\
\text { (2 полосы) }\end{array}$ & $\begin{array}{l}2900-2820 \\
\text { (слабая) } \\
2775-2700 \\
\text { (слабая) }\end{array}$ & 2852 & 2867 & 2852 \\
\hline$\delta\left(=\mathrm{CH}_{2}\right) \mathrm{sp}^{2}$ & $\begin{array}{c}1420-1410 \\
995-985 \\
915-905\end{array}$ & $\begin{array}{l}950, \\
965 \text { пл }\end{array}$ & $\begin{array}{l}964 \text { пл, } \\
980 \text { пл }\end{array}$ & $\begin{array}{c}1436 \\
908\end{array}$ \\
\hline$V_{(C=C)}$ & $\begin{array}{c}1620-1680 \\
\text { узкая }\end{array}$ & 1630 пл. & 1651пл & 1644пл \\
\hline $\begin{array}{l}v_{\mathrm{C}=\mathrm{O}}(\text { альдегиды, кетоны, } \\
\text { карбоновые кислоты) } \\
\text { v }_{(\mathrm{CPh})} \text { арены }\end{array}$ & $\begin{array}{l}\text { 1750-1600 } \\
\text { средняя }\end{array}$ & 1742 & 1756 & $\begin{array}{l}1709 \\
1743\end{array}$ \\
\hline $\begin{array}{l}v_{\mathrm{C}=\mathrm{O}} \text { ароматич. } \\
\text { альдегиды, кетоны }\end{array}$ & $1705-1660$ & 1600,1637 & - & - \\
\hline$\delta\left(\mathrm{CH}_{2}\right)$ & $710-720$ & 722 & 731 & 721 \\
\hline vas (CO) Полуторные & $1430-1470$ & 1458 & - & 1454 \\
\hline vs (CO), vas (CC) & $1540-1600$ & 1600 & - & - \\
\hline
\end{tabular}

Кроме того, именно после 4 сут экспозиции металла в изопропанольном экстракте шрота рапса, как показывают исследования [4], заканчивается формирование адсорбционной пленки на его поверхности. При этом более длительная выдержка образцов в парах экстракта к повышению ингибирующих свойств не приводит.

\section{Выводы}

Исследование состава изопропанольного экстракта шрота рапса показало, что в нем содержится около 20 индивидуальных компонентов, среди которых доминируют гликозиды (сахароза, гуанозин, ксантонозин), сиреневый альдегид, кетон - 3,5-диметоксиацетофенон, стероиды ( $\beta$ и $\gamma$-ситостерол, кампостерол и др.), а также насыщенные и ненасыщенные жирные кислоты, представленные пальмитиновой, олеиновой, линолевой кислотами.

Анализ полученных ИК-спектров подтверждает наличие данных соединений в исследуемом экстракте, а также позволяет предположить, что при адсорбции указанных соединений на поверхности металла возможно образование пленки по донорно-акцепторному механизму.

Анализ компонентного состава остатка экстракта после 4 сут экспозиции показывает, что в нем к этому моменту остаются, главным образом, нелетучие соединения, а именно, некоторые спирты и ароматические вещества, включая стероиды.

\section{Список литературы}

1. El-Etre A.Y., Abdallah M. Natural honey as corrosion inhibitor for metals and alloys. II. C-steel in high saline water // Corrosion Science. 2005. Vol. 47, N2. Pp. 385-390.

2. El-Etre A.Y. Inhibitor of acid corrosion of aluminum using vanillin // Corrosion Science. 2001. Vol. 43. N2. Pp. 1031-1039.

3. Taleb I., Hisham A., Yasmin Al. The effect of Thyme leaves extract on corrosion of mild steel in $\mathrm{HCl} / /$ Progress in Organic Coatings. 2012. Vol. 75. N2. Pp. 456-462.

4. Чигиринец Е.Э., Воробьева В.И., Гальченко Г.Ю. Исследование защитной способности пленок летучих ингибиторов коррозии, разработанных на основе растительного сырья // Вопросы химии и химической технологии. 2011. №4(2). С. 273-276. 
5. Чигиринец Е.Э., Воробьева В.И. Определение противокоррозионной эффективности растительных экстрактов // Научные вести «КПИ». 2010. №6. С. 152-155.

6. Николаева Н.А., Степычева Н.В., Козлов В.А. Изменение физико-химических характеристик рапсового масла в зависимости от сроков вызревания семян и агротехнических факторов в условиях нечерноземья // Химия растительного сырья. 2005. №2. С. 35-40.

7. Воробьева В.И., Чигиринец Е.Э. Разработка летучих ингибиторов атмосферной коррозии на основе экстрактивной части шрота рапса // Экология, неоэкология, охрана окружающей среды и сбалансированное природопользование : материалы I Всеукраинской научной конференции магистров, аспирантов и молодых ученых.. Харьков, 2012. С. 140-141.

8. Ashassi-Sorkhabi H., Shabani B., Aligholipour B., Seifzadeh D. The effect of some Schiff bases on the corrosion of aluminum in hydrochloric acid solution // Applied Surface Science. 2006. Vol. 252. Pp. 4039-4047.

9. Rehan H. H. Corrosion control by water-soluble extracts from leaves of economic plants // Material wissenschaft und Werkstofftechnik, 2003. Vol. 34, N2. Pp. 232-237.

10. Chris O. Akalezi, Conrad K., Enenebaku, Emeka E. Oguzie Inhibition of acid corrosion of mild steel by biomass extract from the petersianthus macrocarpus plant // J. Mater. Environ. Sci. 2013. Vol. 4, N2. Pp. 217-226.

Поступило в редакиию 22 марта 2013 г.

Chigirinets E.E. , Vorob'eva V.I., Berezhnitskaia A.S. STUDYING THE CHEMICAL COMPOSITION OF ALCOHOLIC EXTRACT SCHROTH RAPE

National Technical University of Ukraine "Kyiv Polytechnic Institute", Pobedy ave., 37-4, Kiev, 03056 (Ukraine),

e-mail: corrosionlife@yandex.ru

As the authors found that a promising material for a volatile atmospheric corrosion inhibitor is the use of waste generated in obtaining oil from rapeseed (family Brassicaceae), namely rapeseed meal, appropriate research was qualitative and quantitative determination of its basic compounds. Also found that the inhibition efficiency is extreme character with a maximum protective capacity for 2 hours. Why was it necessary to study changes in the composition of the extract in the evaporation process, and identification of compounds that do not take part in the formation of the film, that is remaining in the non-volatile sludge.

The subject of this study is to extract 2-propanol rapeseed cake extract . The purpose of work - a study of its component composition, namely, volatile and non-volatile compounds.

The volatile chemical composition of the rapeseed cake extract involves glycosides, nucleosides, ketone, aldehyde, fatty acids, sterol and alkaloids. The most important compounds in rapeseed cake are: Guanosine, Sucrose , Xanthosine, 3',5'Dimethox yacetophenone Benzaldehyde, 4-hydroxy-3,5-dimethoxy, Acetic, Oleic, Linoleic and Palmitic acid and Sterols.

Keywords: Steel; Corrosion; Volatile inhibitor; Rapeseed cake extract, 2-propanol extract, glycosides, keton, terpens, aldehyde, Gas Chromatography-Mass Spectrometry.

\section{References}

1. El-Etre A.Y., Abdallah M. Corrosion Science, 2005, vol. 47, no. 2, pp. 385-390.

2. El-Etre A.Y. Corrosion Science, 2001, vol. 43, no. 2, pp. 1031-1039.

3. Taleb I., Hisham A., Yasmin Al. Progress in Organic Coatings, 2012, vol. 75, no. 2, pp. 456-462.

4. Chigirinets E.E., Vorob'eva V.I., Gal'chenko G.Iu. Voprosy khimii i khimicheskoi tekhnologii, 2011, no. 4(2), pp. 273-276. (in Russ.).

5. Chigirinets E.E., Vorob'eva V.I. Nauchnye vesti «KPI», 2010, no. 6, pp. 152-155. (in Russ.).

6. Nikolaeva N.A., Stepycheva N.V., Kozlov V.A. Khimiia rastitel'nogo syria, 2005, no. 2, pp. 35-40. (in Russ.).

7. Vorob'eva V.I., Chigirinets E.E. Materialy I Vseukrainskoi nauchnoi konferentsii magistrov, aspirantov i molodykh uchenykh. Ekologiia, neoekologiia, okhrana okruzhaiushchei sredy i sbalansirovannoe prirodopol'zovanie. [Materials I-Ukrainian scientific conference masters and PhD students and young scientists. Ecology, neoekologiya, environmental protection and that balanced nature]. Kharkiv, 2012, pp. 140-141. (in Russ.).

8. Ashassi-Sorkhabi H., Shabani B., Aligholipour B., Seifzadeh D. Applied Surface Science, 2006, vol. 252, pp. $4039-4047$.

9. Rehan H. H. Material wissenschaft und Werkstofftechnik, 2003, vol. 34, no. 2, pp. 232-237.

10. Chris O. Akalezi, Conrad K., Enenebaku, Emeka E. J. Mater. Environ. Sci., 2013, vol. 4, no. 2, pp. 217-226.

Received March 22, 2013

\footnotetext{
"Corresponding author.
} 